\title{
Linguistische Arbeiten
}

\section{5}

Herausgegeben von Hans Altmann, Peter Blumenthal, Herbert E. Brekle, Gerhard Helbig, Hans Jürgen Heringer, Heinz Vater und Richard Wiese 

Jean-Yves Lalande

\section{Verbstellung im Deutschen und Französischen}

Unter Anwendung eines CAD-basierten Expertensystems

Max Niemeyer Verlag Tübingen 1997 
Die Deutsche Bibliothek - CIP-Einheitsaufnahme

Lalande, Jean-Yves: Verbstellung im Deutschen und Französischen : unter Anwendung eines

CAD-basierten Expertensystems / Jean-Yves Lalande. - Tübingen : Niemeyer, 1997

(Linguistische Arbeiten ; 365) NE: GT

ISBN 3-484-30365-4 ISSN 0344-6727

(C) Max Niemeyer Verlag GmbH \& Co. KG, Tübingen 1997

Das Werk einschließlich aller seiner Teile ist urheberrechtlich geschützt. Jede Verwertung außerhalb der engen Grenzen des Urheberrechtsgesetzes ist ohne Zustimmung des Verlages unzulässig und strafbar. Das gilt insbesondere für Vervielfältigungen, Übersetzungen, Mikroverfilmungen und die Einspeicherung und Verarbeitung in elektronischen Systemen. Printed in Germany.

Gedruckt auf alterungsbeständigem Papier.

Druck: Weihert-Druck GmbH, Darmstadt

Buchbinder: Industriebuchbinderei Hugo Nädele, Nehren 